\title{
Antitumor Activities of the Novel Isosteviol Derivative 10C Against Liver Cancer
}

\author{
AHMED MALKI $^{1}$, AHMED EL-SHARKAWY $^{2}$, MOHAMED EL SYAED $^{2}$ and STEPHEN BERGMEIER ${ }^{3}$ \\ ${ }^{1}$ Biomedical Science Department, Qatar University, Doha, Qatar; \\ ${ }^{2}$ Biochemistry Department, Alexandria University, Alexandria, Egypt; \\ ${ }^{3}$ Department of Chemistry and Biochemistry, Ohio University, Athens, OH, U.S.A.
}

\begin{abstract}
Background/Aim: Hepatocellular carcinoma (HCC) is the most common type of liver cancer and the fifth most common primary malignancy with worldwide increasing incidence. The current study aimed to investigate the anticancer activities of novel isosteviol derivatives towards human HepG2 hepatocellular cancer cells and in an animal model of hepatocellular carcinoma. Materials and Methods: Twelve isosteviol derivatives were screened for their anti-proliferative activities against HepG2 and $I_{50}$ was calculated for all designed derivatives. The impact of the potent isosteviol derivative 10C on HepG2 cells was further studied by MTT assay, Annexin V/PI staining, flow cytometry and western blotting. In vivo studies were performed to assess the anticancer effect of isosteviol derivative 10C on Diethyl Nitrosamine-induced liver cancer in female rats by evaluating the physiological processes. Results: isosteviol derivative 10C induced growth inhibition with $I_{50}$ of $2 \mu M$ mainly through induction of apoptosis in HepG2 cells. Additionally, isosteviol derivative 10C induced $G_{1}$ phase arrest, which was further confirmed by increased expression of cyclin dependent kinase inhibitor $1 \mathrm{~A}$ (CDKN1A, p21). It also increased BAX, BID and PARP-1 and while it reduced pro-CASPASE-3 expression and phosphorylation levels of AKT in HepG2 cells. Furthermore, western blotting data showed that E-cadherin, $\beta$-catenin, VEGF and COX-2 expressions were suppressed by isosteviol derivative 10C in HepG2 cells. The in vivo study demonstrated that dose-dependent treatment of isosteviol derivative 10C led to significant reduction in tumor size compared to the untreated group after the fourth injection
\end{abstract}

Correspondence to: Dr. Ahmed Malki, Biomedical Science Department, College of Health Sciences, Qatar University, Doha, 2713, Qatar. Tel: 97444036557, e-mail: ahmed.malki@qu.edu.qa Permanent address: Biochemistry Department, Faculty of Science, Alexandria University, Alexandria 21521, Egypt.

Key Words: Isosteviol, liver cancer, VEGF, $\mathrm{p} 21$, in vivo. with no significant effects on major physiological processes. Conclusion: Taken together, in vitro and in vivo studies revealed that isosteviol derivative 10C induced apoptosis in HepG2 cells, blocked angiogenic signaling and it did not induce any apparent toxicity towards the treated hosts which merits further investigation at clinical level.

Hepatocellular carcinoma ( $\mathrm{HCC}$ ) is the third leading cause of cancer deaths worldwide, with its incidence recorded the highest in Asia and Africa. Despite significant advances in surgery and chemotherapy, most patients with hepatocellular carcinoma die between 6 months to 1 year after diagnosis (14). Even though HCC patients' short-term prognosis has improved recently, the long-term prognosis remains considerably low, as indicated by the overall survival of 22$35 \%$ at 10 years after treatment $(5,6)$. At present, surgery and chemotherapy are the main treatments for $\operatorname{HCC}(7,8)$ with doxorubicin representing the main chemotherapeutic agent against liver cancer either as single drug or in combination with other chemotherapeutics like cisplatin. However, the current drugs' severe toxicity on healthy hepatocytes make the outcomes to be considerably low $(9,10)$. Therefore, searching for highly efficient anticancer drugs with low toxicity towards healthy cells remains an active area of research. Most cancer chemotherapeutic and chemopreventive drugs act by triggering either apoptosis or transition of the cell cycle, and accordingly, we can measure the tumor cell apoptosis induction as a predictive tool for measuring the efficacy of the chemotherapeutic treatment (11).

Previous studies have reported that Ent-beyeran diterpenoid isosteviol possesses anti-proliferation activities, (12) and prevents growth of cancer cells $(13,14)$. Here we investigated the effects of a series of novel derivatives of isosteviol on proliferation and apoptosis of liver cancer cells (HepG2) as well as N-nitrosodiethylamine-induced liver cancer rats. Apoptosis is a programmed cell death and it plays a great role in balancing cellular replication and death. An increasing amount of evidence suggests that alterations of the normal apoptotic pathways results in neoplastic 
transformation, progression and metastasis (15, 16). Signaling pathways of apoptosis can proceed through two pathways, via death receptors expressed on the plasma membranes of cells and via mitochondria, which contain several proteins that regulate apoptosis (17-20). Through the normal eukaryotic cell cycle, cyclin-dependent kinases (CDKs) regulate the successful completion of one cell cycle event before succession to the next cell cycle event. These regulatory pathways are commonly called cell-cycle checkpoints (21). Progression of mammalian cell cycle is regulated by $\mathrm{CDKs}$ and regulatory subunits cyclins. Cyclin dependent kinase inhibitor 1A (CDKN1A, p21) is a wellknown inhibitor of cell cycle and can arrest the cell cycle progression in $G_{1} / S$ and $G_{2} / M$ transitions by inhibiting CDK4, 6/Cyclin D and CDK2/Cyclin E, respectively. It is believed that the regulation of cell growth by p21 is mediated by control of E2F activity $(22,23)$. The progression of the cell cycle is triggered by partial phosphorylation of $\mathrm{Rb}$ by CDK-Cyclin, and CDKN1A disrupts these interactions and inhibit cell cycle progression (24). CASPASE-3 is considered an important effector protease that is cleaved and activated during apoptosis (25). CASPASE-3 cleaves a variety of cellular substrates, most notably Poly(ADP-ribose) polymerase (PARP) which acts to help repair single-strand DNA nicks and cleaved PARP is a useful marker of apoptosiss (26). High level of PARP can activate the release of apoptosis-inducing factor (AIF). AIF is transferred from the cytoplasm to the nucleus and can promote DNA fragmentation and chromatin aggregation in the nucleus, resulting in apoptosis (27-33).

Cyclooxygenase $(\mathrm{COX})$, which plays a major role in physiological and pathological regulation $(34,35)$ consists of two subunits: cyclooxygenase-1 (COX-1) and cyclooxygenase-2 (COX-2) with the later not expressed in the physiological condition, but rather its expression is induced by pathological stimuli, such as cancer and hormones. It is well documented that COX-2 accelerates cancer invasion and metastasis through inhibiting cancer cell apoptosis and promoting tumor angiogenesis (36-40). High expression of COX-2 is closely correlated with poor prognosis for various types of cancers (41-43). Moreover, the enzyme can stimulate proliferation, inhibit apoptosis, increase invasiveness and induce angiogenesis through inducing the expression of some angiogenic factors as vascular endothelial growth factor (VEGF) $(44,45)$.

Angiogenesis is considered a key process in tumor invasiveness and metastasis. It has been implicated in poor prognosis and relapse of the vast majority of malignancies, including gastrointestinal neoplasms. VEGF is the most known and efficient angiogenic growth factor. It is known to accelerate endothelial cellular proliferation and migration, vascular permeability, and inhibit apoptosis whereas its inhibition results in suppression of tumour growth (46).
In this study, we investigated the impact of the isosteviol derivative $10 \mathrm{C}$ on liver cancer cells (HepG2) by 3-(4,5dimethylthiazol-2-yl)-2,5-diphenyltetrazolium bromide (MTT) assay, Annexin V/PI staining, flow cytometry, western blotting analysis. We also investigated the protective effect of isosteviol derivative 10 on DEN-induced liver cancer in female rats.

\section{Materials and Methods}

Cell culture and drug treatment. The human liver cancer cell line HepG 2 was obtained from the American Type Culture Collection (ATCC, Manassas, VA, USA). HepG 2 cells were cultured in DMEM growth medium (GIBCO, New York, NY, USA) supplemented with $10 \%$ heat-inactivated fetal bovine serum, $1 \%$ penicillin/streptomycin and $2 \% \mathrm{~L}$-glutamine. Cells were maintained in monolayer in $\mathrm{T} 75$ flasks and incubated at $37^{\circ} \mathrm{C}$ in an atmosphere of $95 \%$ air and $5 \% \mathrm{CO}_{2}$. Isosteviol derivative was at $2 \mu \mathrm{M}$ concentration and dissolved in suitable media.

MTT assay. Cell viability was measured by MTT bromide mitochondrial activity assay. Briefly, $4-5 \times 10^{3}$ cells /well in $100 \mu \mathrm{l}$ of medium were seeded in a 96-well plate for $24 \mathrm{~h}$ prior to drug treatment. The medium was then changed to medium with different concentrations of isosetviol deivatives. After $24 \mathrm{~h}, 10 \mu \mathrm{l}$ of $5 \mathrm{mg} /$ $\mathrm{ml}$ MTT reagent was added to each well and cells were incubated for $4 \mathrm{~h}$. After incubation, $100 \mu \mathrm{l}$ of detergent reagent was added to each well to dissolve the formazan crystals. The absorbance was determined at $570 \mathrm{~nm}$. Cells without analogs were used as controls. Each assay was performed in triplicate and standard deviation was determined.

Annexin V/PI staining. Detection of apoptosis was conducted using the annexin V-FITC/PI apoptosis detection kit according to manufacturer's protocol. Briefly, the treated and untreated cells, were harvested after $24 \mathrm{~h}$ and washed twice with cold PBS. The cell pellets were re-suspended in $500 \mu \mathrm{l}$ of $1 \mathrm{x}$ binding buffer at a concentration of $1 \times 10^{6}$ cells $/ \mathrm{ml} .5 \mu \mathrm{l}$ of annexin V-FITC and $5 \mu \mathrm{l}$ of PI were added into the cell suspension, followed by gentle vortexing. The staining samples were incubated for $10 \mathrm{~min}$ at room temperature in darkness. Samples were analyzed by a FACS caliber flow cytometer (BD Biosciences, San Jose, CA, USA) using the software supplied in the instrument.

Flow cytometric analysis. Cells were seeded at a density of 3-5 $\times 10^{5}$ per $10 \mathrm{~cm}$ plate and incubated for $24 \mathrm{~h}$ before treatment. Media were changed to media containing $2 \mu \mathrm{M}$ Isosteviol derivative 2; $24 \mathrm{~h}$ after treatment, cells were harvested by trypsinization. The cells were washed with PBS and fixed with ice cold $70 \%$ ethanol while vortexing. Finally, the cells were washed and re-suspended in PBS containing $5 \mu \mathrm{g} / \mathrm{mL}$ RNase A (Sigma, St. Louis, MO, USA) and 50 $\mu \mathrm{g} / \mathrm{ml}$ propidium iodide (Sigma) for analysis. Cell-cycle analysis was performed using FACScan Flow Cytometer (Becton Dickson) according to the manufacturer's protocol. Windows multiple document interfaces (WinMD) software was used to calculate the cell-cycle phase distribution from the resultant DNA histogram, and data were expressed as a percentage of cells in the $G_{0} / G_{1}$ and $G_{2} / M$ phases. The apoptotic cells were determined on the DNA histogram as a subdiploid peak. 
Western blotting. Total cell lysates from HepG2 were extracted using lysis buffer (50 mM Tris-HCl, $\mathrm{pH} 7.4,150 \mathrm{mM} \mathrm{NaCl}, 1 \%$ Triton X-100, $0.1 \%$ sodium dodecyl sulfate (SDS), $1 \mathrm{mM}$ ethylene diamine tetra acetic acid (EDTA), $1 \mathrm{mM} \mathrm{Na} \mathrm{VO}_{4}, 1 \mathrm{mM} \mathrm{NaF}$, protease inhibitor cocktail). The proteins were separated on 4-12\% Bis-Tris gels and electro-transferred onto a Hybond ECL transfer Membrane (GE Healthcare Bio-Science, Piscataway, NJ, USA). The membranes were blocked with $5 \%$ nonfat dry milk and immunoblotted with antibodies for E-cadherin, beta catenin, CDKN1A (p21), proCASPASE-3, PARP-1, AKT, BAX, pAKT, COX-2 and VEGF (Cell signaling, Beverly, MA, USA). Horseradish peroxidase-conjugated secondary anti-mouse or rabbit antibodies (AbD serotec, Kidlington, UK) were incubated. The protein expression was visualized by enhanced chemiluminescence (ECL) systems (Amersham Pharmacia, Piscataway, NJ, USA).

Animal treatment and in vivo chemotherapy. Virgin female Wistar Albino rats (animal house, Faculty of Medicine, Egypt) were obtained at 60 days of age, weighing $\sim 120 \mathrm{~g}$. The animals were housed in plastic cages (five rats/cage) in a controlled environment with temperature maintained at $25-27^{\circ} \mathrm{C}$ and a $12 \mathrm{~h}$ light/dark cycle. They were acclimatized for seven days before the start of the experiment, with food and water provided ad libitum. Rats were housed four per cage in conditioned rooms at $20 \pm 2^{\circ} \mathrm{C}$, kept under an automatic 12 hours of light/12 hours of darkness schedule, and given pellets and tap water ad libitum. All animal studies were conducted in accordance with the NIH Guide for the Care and the Use of Laboratory Animal. DEN (Sigma) was dissolved in $0.85 \%$ $\mathrm{NaCl}$ solution and acidified (acetic acid) to $\mathrm{pH}$ 5.0. The concentration was then adjusted to $200 \mathrm{mg} / \mathrm{kg}$ body weight/rat . Heparin-treated blood $(0.2 \mathrm{ml})$ was obtained by cardiac puncture from rats lightly anesthetized with ether. Animals were palpated for detection of liver tumors after injection and the animals were examined by palpation for tumor masses thrice weekly post administration of carcinogen. Tumor sizes were measured with a caliper and their growth and histological parameters were recorded.

Animal experimental design. At 65 days of age, the female rats were divided into the following groups. I-Healthy Controls $(n=10)$ without DEN induction; II-DEN controls $(n=20)$ received weekly an injection of DEN ( $200 \mathrm{mg} / \mathrm{kg}$ body weight/rat) and thrice per week intragastric injections of $\mathrm{CCl} 4(0.5 \mathrm{mg} / \mathrm{Kg}$ body weight $)$ dissolved in sunflower oil and $0.05 \%$ PB replaced tab water daily for 24 weeks; III-DEN and treated with isosteviol 10C $(n=20)$ received weekly an injection of DEN $200 \mathrm{mg} / \mathrm{kg}$ body weight $/ \mathrm{rat}$ ) and thrice per week intragastric injections of CCl4 $(0.5 \mathrm{mg} / \mathrm{Kg}$ body weight) dissolved in sunflower oil and $0.05 \%$ PB replaced tab water daily for 24 weeks and observed for tumor development, at which isosteviol 10C was injected at different time intervals for 60 days.

Histopathological examination and biochemical analysis of serum. The organs were prepared as paraffin-embedded tissue glass slides stained with hematoxylin and eosin and evaluated according to the National Toxicology Program standards. A complete cross-section of each liver and kidney, when possible, was evaluated. For liver, two cross-sections, one of each of the two largest liver lobes were examined. For kidneys, an entire cross-section (left longitudinal, right transverse) was evaluated. The entire sections on the slides (all fields) were evaluated under blinded conditions for lesions and scored (graded) on a subjective basis compared to control animals.
Table I. $I C_{50}$ of the synthesized isosteviol derivatives.

\begin{tabular}{lcc}
\hline Derivatives & $\mathrm{R}$ (any group) & $\begin{array}{c}\text { Inhibitor concentration } \\
\mathrm{IC}_{50}(\mu \mathrm{M})\end{array}$ \\
\hline 7 & & 18 \\
$8 \mathrm{a}$ & $\mathrm{Ph}$ & 30 \\
$8 \mathrm{~b}$ & $\mathrm{CH}_{3}$ & 28 \\
$8 \mathrm{c}$ & $n-\mathrm{C}_{7} \mathrm{H}_{15}$ & 44 \\
$8 \mathrm{~d}$ & $i-\mathrm{Pr}$ & 20 \\
$8 \mathrm{e}$ & $\mathrm{CH}_{2} \mathrm{OPh}$ & 19 \\
$9 \mathrm{a}$ & $\mathrm{Ph}$ & 15 \\
$9 \mathrm{~b}$ & $4-(\mathrm{MeC}(\mathrm{O}))-\mathrm{C}_{6} \mathrm{H}_{4}$ & 25 \\
$9 \mathrm{c}$ & $n-\mathrm{C} 3 \mathrm{H} 7$ & 40 \\
$9 \mathrm{~d}$ & $4-(\mathrm{MeO})-\mathrm{C}_{6} \mathrm{H}_{4} \mathrm{CH}_{2}$ & 33 \\
$9 \mathrm{e}$ & $\mathrm{CH}_{2} \mathrm{Ph}_{2}$ & 40 \\
$10 \mathrm{C}$ & $\mathrm{n}-\mathrm{C}_{7} \mathrm{H}_{15}$ & 2 \\
\hline
\end{tabular}

The grades were as follows: $1=$ minimal, $2=$ mild, $3=$ moderate, $4=$ marked, and $-=$ no pathological changes. Serum biochemistry parameters analyzed included blood urea nitrogen (BUN), aspartate amino transferase (AST), amino alanine transferase (ALT), creatine kinase (CK) and alkaline phosphatase (AP). Blood was collected from the posterior vena cava of control rats that were either treated with water and treated rats administered $90 \mathrm{mg} / \mathrm{kg}$ isosteviol derivative $10 \mathrm{C}$ after 60 days of treatment.

Statistical analyses. All the assays described above were repeated more than once. The quantification assays were performed in triplicate and data were calculated and are presented as means \pm standard deviation. Data was either analyzed by unpaired Student $t$-test or one-way ANOVA with Tukey's post-hoc test, depending on the nature of the assays. Significance was set at $p<0.05$.

\section{Results}

Isosteviol derivative $10 C$ reduces proliferation and induces apoptosis of HepG2 cells. The effect of the synthesized compounds on the growth of HepG2 cell line was shown in Table I, the $\mathrm{IC}_{50}$ was calculated for all tested isosteviol derivatives. Based on the results in Table I, isosteviol derivative $10 \mathrm{C}$ was the most potent with $\mathrm{IC}_{50}$ of $2 \mu \mathrm{M}$ in reduction of HepG 2 proliferations, the chemical structure of the designed isosteviol derivative is shown in (Figure 1A). Microscopic examination was performed in order to ascertain induction of apoptosis by $2 \mu \mathrm{M}$ of isosteviol derivative $10 \mathrm{C}$. In HepG2 cells, the assay revealed the characteristic features of apoptosis, such as blebbing, cell shrinkage and nuclear fragmentation (Figure 1B). Additionally, morphological changes of cell apoptosis such as condensation of chromatin and nuclear fragmentation were clearly observed by DAPI staining after $24 \mathrm{~h}$ of isosteviol derivative $10 \mathrm{C}$ treatment (Figure 1C). The apoptotic effect of compounds 10C was confirmed by Annexin-V FITC/PI (AV/PI) dual staining 
A<smiles>CCCCCCCC(=O)OC[C@]1(C)CC[C@]23C[C@H](O)C4(C)CCC2[C@@]1(C)CCC[C@]4(C)C3</smiles>

C

C

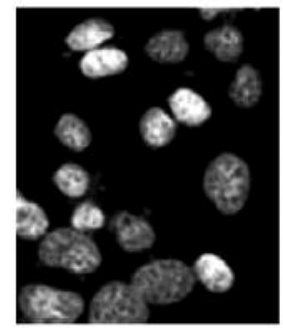

$10 \mathrm{c}$

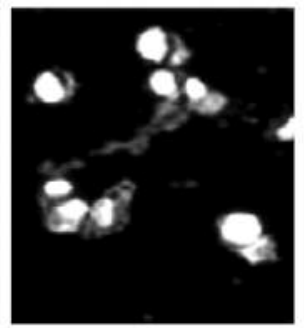

B

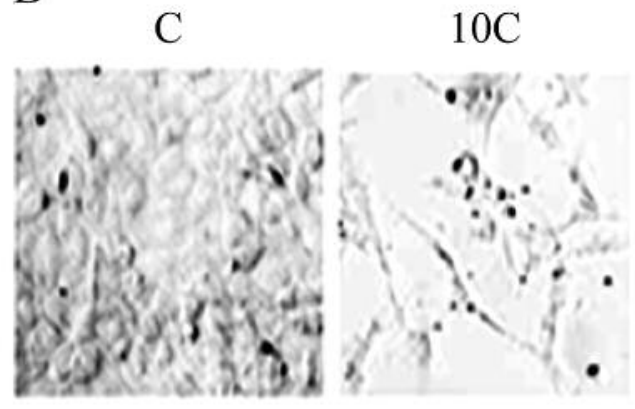

D

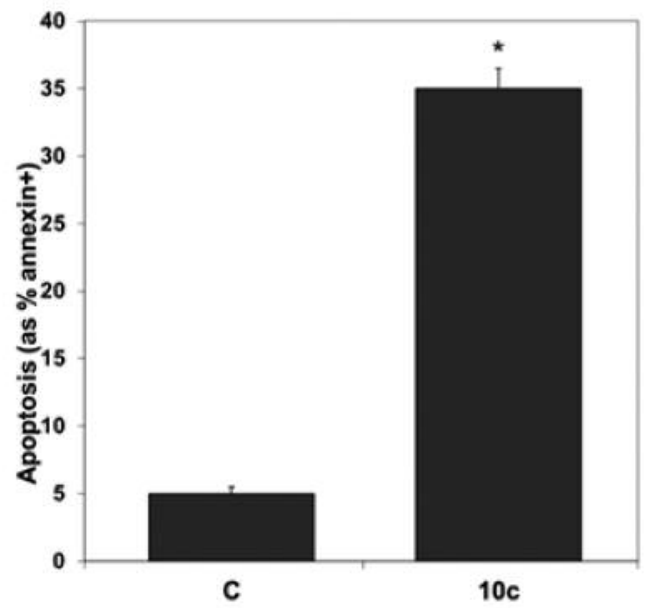

Figure 1. Impact of isosteviol derivative on apoptosis. Structure of isosteviol derivative (A). HepG2 cells were treated with $2 \mu M$ of derivative and morphological appearance of apoptosis was examined $(B)$. Nuclear alterations were observed by DAPI staining and fluorescence microscopy $(\times 100)$ (C). Percentage of apoptosis in HepG2 cells was determined after treating HepG2 with $2 \mu M$ isosteviol derivative for $24 h$. (D). Each data point is the mean $\pm S D$ of three independent experiments.

assay. In this assay, HepG2 cells were treated with $2 \mu \mathrm{M} 10 \mathrm{C}$ for $24 \mathrm{~h}$. Data in Figure 1D revealed that HepG2 cells treated with $10 \mathrm{C}$ increased the percent of apoptotic cells by 7 -fold compared to the untreated control cells.

Isosteviol derivative arrests HepG2 cells in $G_{1}$ phase. Apoptosis is frequently associated with proliferating cells, implying the existence of molecules in late $G_{1}$ and $S$ phase whose activities facilitate execution of the apoptotic process. Flow cytometry was used to examine the effects of isosteviol derivative on cell-cycle checkpoints, as well as cell proliferation and apoptosis. The percentage of cells in $\mathrm{G}_{1}, \mathrm{~S}$, $\mathrm{G}_{2}$, and apoptosis were determined after treating HepG2 cells with $2 \mu \mathrm{M}$ of isosteviol derivative (Figure 2A). Isosteviol derivative induced apoptosis by arresting cells in the $\mathrm{G}_{1}$ phase $(55 \%)$ compared with the untreated group (30\%). The arrest in the $G_{1}$ phase was consistent with increased expression of CDKN1A (p21) (6-fold increase) in HepG2 cells treated with $2 \mu \mathrm{M}$ of Isosteviol derivative compared to the untreated group (Figure 2B). Cell death was also assessed with flow cytometry after double staining with annexin $\mathrm{V}$ and PI. The results showed that about $51.7 \%$ of the total population were viable cells, $48.3 \%$ represents cells in early apoptosis, late apoptosis and dead cells. Consistent with the progression of apoptosis, late apoptotic cells become dominant at $24 \mathrm{~h}$ (Figure 2C). These findings confirmed that isosteviol derivative 10C induced apoptosis of HepG2 cells.

Isosteviol derivative $10 C$ alters apoptotic proteins and reduced pro-CASPASE-3 activity in HepG2 cells. We investigated the effect of Isosteviol derivatives 10C on proapoptotic proteins BAX and BID. Our data revealed that 
A

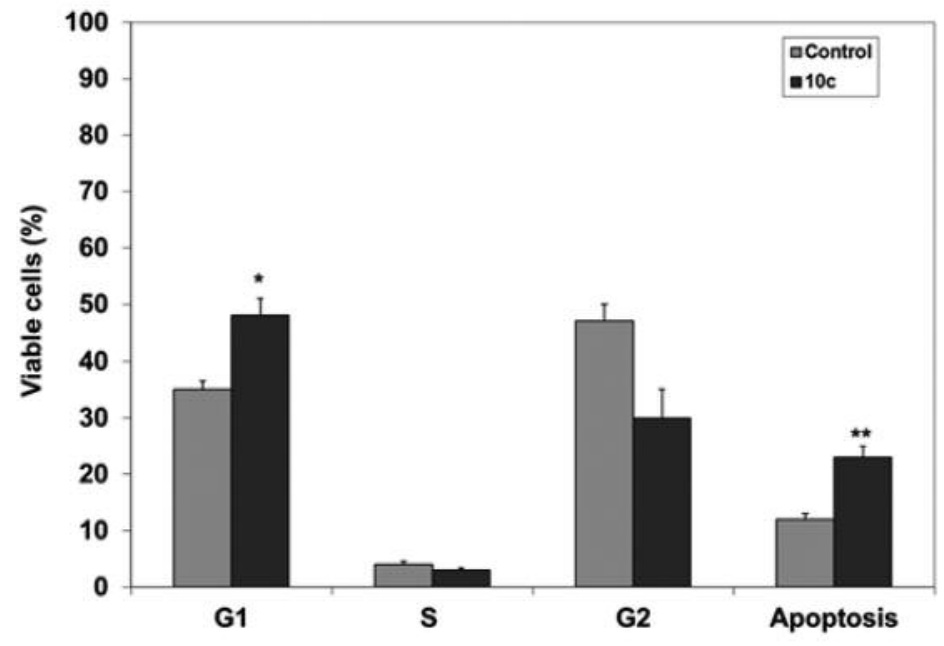

$\mathrm{B}$

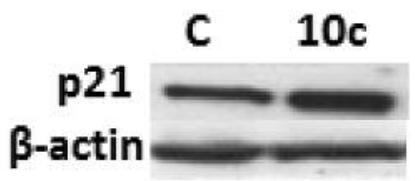

$\mathrm{C}$
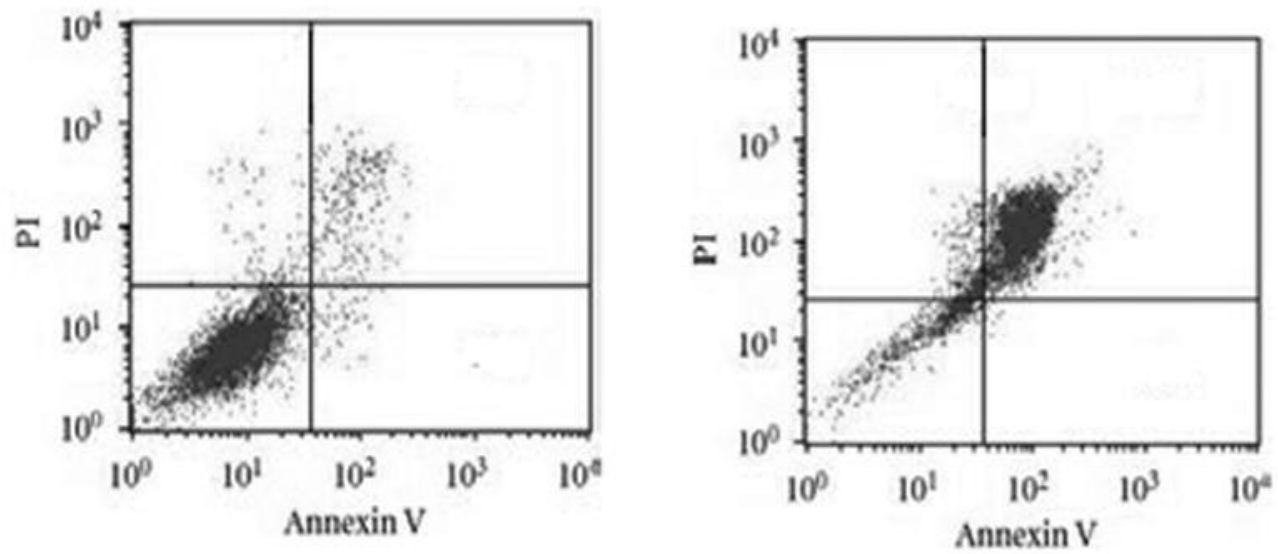

Figure 2. Impact of isosteviol derivative 10C on cell cycle in HepG2 cells. The percentage of cells in each cell cycle phase was determined in HepG2 cells after treatment with $2 \mu \mathrm{M}$ isosteviol derivative $10 \mathrm{C}$ for $24 \mathrm{~h}(\mathrm{~A})$. Each data point is the mean $\pm S D$ of three independent experiments. p21 protein expression level was determined after treating HepG2 with $2 \mu \mathrm{M}$ of isosteviol for $24 \mathrm{~h}(\mathrm{~B})$. HepG2 cells were treated with isosteviol derivative $2 \mu \mathrm{M}$ for $24 \mathrm{~h}$, lower right quadrant, early apoptosis cells, that is, Annexin V-FITC-positivel PI-negative cells; upper right quadrant, necrosis or late-apoptotic cells, that is, Annexin V-FITC-positive/PI-positive cells (C).

$10 \mathrm{C}$ increased expression level of BAX and Bis by 4- and 2-fold, respectively. To examine the possible involvement of the PI3K/AKT pathway in $10 \mathrm{C}$ isosteviol-induced apoptosis, we assessed phosphorylated AKT levels during Diterpene-induced apoptosis in HepG2 cells (Figure 3A). Western blotting analysis showed that AKT was constitutively active in the HepG2 cells and that phosphorylated AKT levels were significantly decreased in response to $10 \mathrm{C}$ treatment. However, there were no effects on steady-state levels of total AKT protein in the HepG2 cells treated with isosteviol derivatives 10C. Hallmarks of the apoptotic process include the activation of cysteine proteases, which represent both initiators and executors of cell death. Isosteviol derivative 10C. CASPASE-3 is a known effector caspase that is activated by caspase- 9 thereby functioning in apoptosis by cleaving DNA fragmentation factor 45 (DFF45). Furthermore, proCASPASE-3 enzyme activity was significantly reduced by 4-fold at $24 \mathrm{~h}$ in HepG2 cells treated with isosteviol derivative $10 \mathrm{C}$ compared to the untreated control. These data were further confirmed by increased PARP1 cleavage up on treatment of HepG2 cells with isosteviol derivatives $10 \mathrm{C}$ by approximately three fold respectively compared to untreated group (Figure 3B). 
A

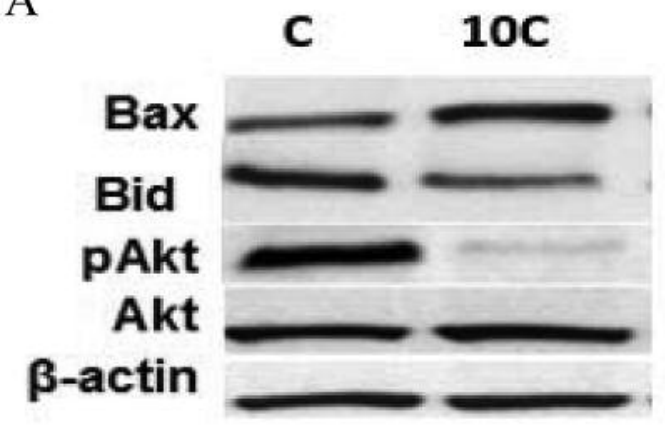

B

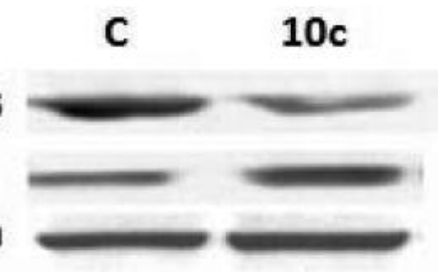

Procaspase-3

PARP-1

$\beta$-actin

Figure 3. Isosteviol derivative 10C induced apoptosis via AKT signaling and activation of caspases 9 and 3. HepG2 cells treated with isosteviol derivative 10C for $24 \mathrm{~h}$ and cells were harvested to investigate expression of $B A X, B I D, A K T$ and pAKT by Western blotting analysis (A). 10C reduced pro-CASPASE-3 activity and induced Parp-1 cleavage. Proteins were extracted 24 hrom HepG2 cells and were immunoblotted for ProCASPASE-3 using appropriate antibodies, cleaved (80KD) PARP-1 fragment were immunoblotted at $24 \mathrm{~h}$. $\beta$-actin is used as control (B).

Isosteviol derivative attenuates the expression of Ecadherin and beta catenin in HepG2 cells. There are evidences for the role of E-cadherin in apoptosis in cancer cells. In this regards, we examined the role of E-cadherin in isosteviol-induced apoptosis in HepG 2 cells. As shown in Figure 4A, isosteviol derivative attenuated the expression of E-cadherin and $\beta$-catenin by western blotting analysis. We also confirmed that red color expression for E-cadherin around cell membrane or $\beta$-catenin was effectively attenuated in isosteviol derivative treated-HepG2 cells compared to untreated control by immunofluorescence assay (Figure 4A). Additionally, expression of COX-2 and VEGF proteins was reduced upon treatment of HepG2 cells with 10C for 24 hours compared to control cells (Figure 4B).

In vivo study. To assess the preventive effect of isosteviol derivative on development and progression of liver cancer, isosteviol derivative was examined for toxic effects. Investigation of the acute toxicity by $\mathrm{LD}_{50}$ determination, is considered the first step in the toxicological investigation of an unknown substance. $\mathrm{LD}_{50}$ was determined by arithmetic method of Karbar. After fourteen days of oral dose treatment
A

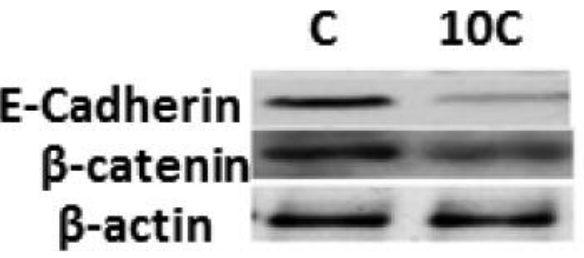

B

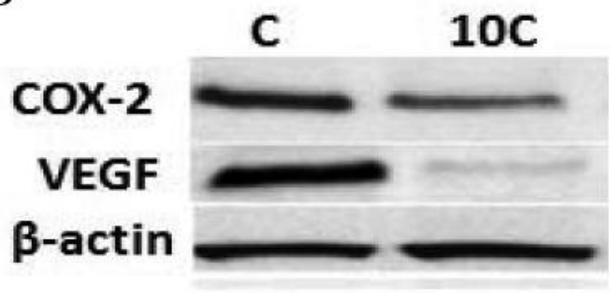

Figure 4. Isosteviol derivative 10C attenuated the expression of metastatic proteins. HepG2 cells treated with isosteviol derivative 10C $24 \mathrm{~h}$ and cells were harvested to investigate expression of E-cadherin, beta-catenin (A), COX-2 and VEGF (B). $\beta$-actin is used as control.

with isosteviol derivative, there were no deaths recorded in $100 \mathrm{mg} / \mathrm{kg}$ doses. During the observation period, animals did not exhibit any variations in general appearance and motor activity, and there was no death in rats tested during the period of observation. Oral administration of isosteviol derivative higher than $100 \mathrm{mg} / \mathrm{kg}$ doses caused death in the tested groups during the first $24 \mathrm{~h}$ of observation (data not shown). The median lethal dose $\mathrm{LD}_{50}$ of 50 was calculated using the following equation: $\mathrm{LD}_{50}=$ Least lethal dose $-\Sigma$ (a.b)/ $\mathrm{N}$, where $\mathrm{N}$ is the number of animals in each group, a is the dose difference and $b$ the mean mortality. The histopathological evaluation of liver and kidney showed no fatty liver changes at sublethal dose and moderate changes at lethal dose of isosetviol derivative 10C and there are mild liver atrophy at sublethal dose. Histopathological observations of kidney showed no changes between control and treated groups for both doses (data not shown).

Impact of isosteviol derivative on liver function markers. The activities of serum AST, ALT, ALP and GGT were found to be significantly higher in DEN-treated rats when compared to control animals. Elevated activities of serum AST, ALT, ALP and GGT observed in DEN-treated rats may be due to DEN-induced hepatic damage and the subsequent leakage of these enzymes into the circulation. Data in Table II show that rats with liver cancer and untreated (group II) had a significant $(p<0.01)$ increase in serum levels of AST, ALT and ALP compared to normal rats in group I (Table II). Isosteviol derivative administration to group IV caused 
Table II. Effect of Isosteviol derivative 10C on serum activities of liver marker enzymes in experimental groups of rats. Data are presented as mean \pm S.E.M $(N=10)$.

\begin{tabular}{lccccc}
\hline Group & Treatment & ALT(U/L) & AST(U/L) & ALP(U/L) & GGT(U/L) \\
\hline I & Control & $25 \pm 0.316$ & $35 \pm 0.324$ & $150 \pm 0.435$ & $25 \pm 0.999$ \\
II & DEN $\left(200 \mathrm{mg} / \mathrm{kg}+\mathrm{PB} 0.05 \%+\mathrm{CCl}_{4}(0.5 \mathrm{ml} / \mathrm{kg})\right.$ & $90 \pm 0.416^{* *}$ & $110 \pm 0.446^{* *}$ & $420 \pm 0.394^{* *}$ & $200 \pm 0.630^{* * *}$ \\
III & Isosteviol derivative $(2 \mu \mathrm{M} / \mathrm{kg})+\mathrm{DEN}+\mathrm{PB}+\mathrm{CCl} 4$ & $40 \pm 0.398^{*}$ & $40 \pm 0.448^{*}$ & $220 \pm 0.392^{*}$ & $100 \pm 0.472^{*}$ \\
\hline
\end{tabular}

ALT, Alanine transaminase; AST, aspartate transaminase; ALP, alkaline phosphatase; GGT, gamma-glutamyl transpeptidas; DEN, Nnitrosodiethylamine; Group II, represent cancer control group. ${ }^{*} p<0.05$ compared to group II (DEN-treated), ${ }^{*} p<0.01$ compared to group I (control), $* * * p<0.001$ as compared to group I (control).

Table III. Effect of Isosteviol derivative 10C on serum levels of total protein, albumin, total bilirubin and (AFP) in experimental groups of rats. Data are presented as mean \pm S.E.M $(n=10)$.

\begin{tabular}{|c|c|c|c|c|c|}
\hline Group & Treatment & Total protein $(\mathrm{g} / \mathrm{dl})$ & Albumin $(\mathrm{g} / \mathrm{dl})$ & Total Bilirubin $(\mathrm{mg} / \mathrm{dl})$ & $\operatorname{AFP}(\mathrm{ng} / \mathrm{ml})$ \\
\hline I & Control & $8 \pm 0.322$ & $4 \pm 0.222$ & $1 \pm 0.251$ & $5 \pm 0.504$ \\
\hline II & DEN $\left(200 \mathrm{mg} / \mathrm{kg} 0+\mathrm{PB} 0.05 \%+\mathrm{CCl}_{4}(0.5 \mathrm{ml} / \mathrm{kg})\right.$ & $6 \pm 0.313 * * *$ & $2 \pm 0.195 * * *$ & $3 \pm 0.222 * * *$ & $110 \pm 0.612 * * *$ \\
\hline III & Isosteviol derivative $10 \mathrm{C}(2 \mu \mathrm{M} / \mathrm{kg})+\mathrm{DEN}+\mathrm{PB}+\mathrm{CCl}_{4}$ & $7 \pm 0.390 *$ & $4 \pm 0.190 *$ & $1.1 \pm 0.242 *$ & $6 \pm 0.549 *$ \\
\hline
\end{tabular}

${ }^{*} p<0.05$ compared to group II (DEN-treated), $* * p<0.01$ as compared to group I (control), ${ }^{* * *} p<0.001$ as compared to group I (control).

significant reduction $(p<0.05)$ in serum level of AST, ALT and ALP as compared to the positive control group (group II). Results in Table II showed that rats with hepatocellular carcinoma (group II) had significant decrease $(p<0.001)$ in serum level of total protein and albumin compared to normal rats (group I). Isosteviol derivative administration caused significant $(p<0.05)$ increase in serum level of total protein and albumin in group III as compared to the untreated group (group II) (Table III). DEN administration significantly $(p<0.001)$ increased total bilirubin in group II, compared to their control counterparts. Isosteviol derivative significantly reduced total bilirubin, $(p<0.05)$ when compared to the DEN-treated group (Table III). Significant increase $(p<0.001)$ was observed in serum levels of the tumor marker protein AFP and GGT in group (II) as compared to control group (group I). Isosteviol derivative supplementation for 4 weeks resulted in significant decrease of AFP and GGT levels $(p<0.05)$ (Table III).

Isosteviol derivative reduces tumorigenicity in DEN-treated rats. Isosteviol derivative $10 \mathrm{C}$ was evaluated at the maximum tolerated dose and administration was scheduled for four injections from day one of maximum tumor size until the fourth week. Tumor volume (V) was recorded and determined by the equation $\left(\mathrm{LXW}^{2}\right) / 2$ in which $\mathrm{L}$ is the length and $\mathrm{W}$ is the width of the tumor. Data in Table IV demonstrates the effectiveness of the Isosteviol derivative $10 \mathrm{C}$ injection on liver cancer rat model as the tumor volumes
Table IV. Comparison of tumor volumes for untreated and isosteviol derivative $10 \mathrm{C}$ treated groups.

\begin{tabular}{lcccc}
\hline \multicolumn{2}{l}{ Tumor volume $\left(\mathrm{cm}^{3}\right)$} & Untreated & Treated & $p$-Value \\
\hline 1st week & Mean \pm SD & $4.5 \pm 0.9$ & $2.5 \pm 0.2$ & $0.012^{*}$ \\
2nd week & Mean \pm SD & $5.5 \pm 1.07$ & $1.8 \pm 0.4$ & $0.016^{*}$ \\
3rd week & Mean \pm SD & $7.4 \pm 1.3$ & $1.6 \pm 0.03$ & $0.013^{*}$ \\
4th week & Mean \pm SD & $7.9 \pm 1.3$ & $1.3 \pm 0.04$ & $0.010^{*}$ \\
\hline
\end{tabular}

* Statistically significant at $p \leq 0.05$.

of the treated group were significantly decreased after several injections. After the first week injection the tumor volume is reduced $44.4 \%$ and tumor volume gradually decreased to $83 \%$ after fourth week injection.

\section{Discussion}

HCC is a cancer originating in liver cells and considered as one of the most common types of tumour (47). Globally, HCC is the fifth most common cause of cancer in men and the eighth common cause of cancer in women and it accounts for $5.4 \%$ of all cancers approximately $(47,48)$. Unfortunately, conventional systemic therapies as cytotoxic agents or hormonal compounds have not shown any promising survival results in advanced HCC (49). Therefore, 
finding a new medical compounds and antitumor agents and studying their therapeutic values has become an important matter of great significance. In the present study, we examined the effect of twelve isosteviol derivatives on proliferation of HepG2 cell lines. Our data showed that treatment with $2 \mu \mathrm{M}$ isosteviol derivative $10 \mathrm{C}$ for $24 \mathrm{~h}$ suppressed viability of cultured HepG2 cells.

Apoptosis is an important mechanism to kill tumor cells (50). The increase in mitochondrial calcium induce apoptosis that results in loss of membrane potential expansion of the matrix and rupture of the outer mitochondrial membrane (51). Isosteviol derivative induced apoptosis of HepG2 cells as shown by the Annexin V/PI assay.cyclin dependent kinase inhibitor 1A (p21), a CDK inhibitor, is a p53-inducible protein that blocks the cell-cycle progression in the $G_{1} / S$ phase (52). Thus, the isosteviol derivative $10 \mathrm{C}$ induced upregulation of p21 might have resulted in activation of downstream effectors of $\mathrm{p} 53$-dependent $\mathrm{G}_{1} / \mathrm{S}$ arrest. As a result, repression of cell proliferative genes resulted from the complex between the hypo-phosphorylated form of retinoblastoma protein $(\mathrm{pRb})$ with $\mathrm{E} 2 \mathrm{~F}$ transcription factor (53). Based on our data, the arrest in $\mathrm{G}_{1}$ phase was confirmed by increased expression of cyclin-dependent kinase inhibitor 1A (p21) (by four-fold). Two isoforms of COXs have been identified, COX-1 and COX-2, both catalyzing the same enzymatic reaction. Both are regulated and function differently, despite their structural similarity (54). Inflammatory and mitogenic stimuli induce the expression of COX-2 resulting in increased prostaglandin synthesis (PG) in inflamed and neoplastic tissues. COX is the key enzyme in the conversion process of arachidonic acid to prostaglandins, which in turn plays a central role in inflammation. COX-2 upregulation has been detected in HCC (55-57) and it have carcinogenic effects $(58,59)$ achieved either by producing mediators that regulate cellular growth or directly. It can also induced induce angiogenesis via VEGF and PG production (55- 61) and inhibit apoptosis by inducing the antiapoptotic factor $\mathrm{Bcl}-2$ as well as activating antiapoptotic signaling through AKT/PKB. In the present study, the expression of COX-2 and VEGF were reduced up on treatment of HepG2 cells by isosteviol analogue 10C for $24 \mathrm{~h}$ compared to control.

Therefore, our data imply that reduced COX-2 expression can contribute to $\mathrm{HCC}$ development and progression inhibition either through induction of apoptosis or inhibition of angiogenesis. Furthermore, COX-2 may be a therapeutic target for HCC because of the high expression rate of COX2 in HCC lesions.

We further investigate the effect of isosteviol derivative 10C on caspase 3 and PARP1 expression levels as a possible mechanism of HepG-2 induced apoptosis. PARP is a zincfinger DNA-binding protein which catalyzes the synthesis of poly (ADP-ribose) from its substrate-NAD+. It is implicated in the maintenance of genomic stability and DNA damagetriggered signaling cascade. It can be selectively cleaved by caspase during apoptosis and become incapable of responding to DNA damage. Generally, it was believed that PARP cleavage was catalyzed by CASPASE-3 $(62,63)$, but PARP cleavage by caspase-7 has also been reported (64). The PARP cleavage has been regarded as an evidence of caspase activation and has been widely used as a hallmark of cell apoptosis as it is one of the potential target molecules of effector caspases. Our data showed that upon $24 \mathrm{hrs}$ treatment with isosteviol 10C in HepG2 cells, the activation of CASPASE-3 enzyme increased and the level of the inactive cleaved $86 \mathrm{KD}$ fragment of PARP-1 increased. These results indicated that isosteviol derivative $10 \mathrm{C}$ induce caspase 3 dependent apoptosis as a possible apoptotic mechanism in HepG2.

$\beta$-Catenin is a structure protein in the cadherin mediated cell-cell adhesive system as a regulator (65), and plays an important role in the generation/differentiation of tissues as well as in the repair of normal tissues. It is also known to act as a mediator in the Wingless/Wnt signal transduction pathway (66). In HCC, accumulation of $\beta$-catenin was present in the early stage of HCC (67). Our data clearly showed that Isosteviol derivative $10 \mathrm{C}$ treatment attenuated the expression of $\beta$-catenin and E-cadherin in the nucleus and led to strong staining in the cell membrane and cellular junctions compared to untreated groups. The previous studies investigated the correlation between $\beta$-catenin expression and the differentiation grades of $\mathrm{HCC}$, and prognostic roles of $\beta$-catenin expression in HCC (68-70). After evaluating the effects of our derivative on proliferation, apoptosis, and cell-cycle progression and apoptotic proteins, we chose to study the impact of the isosteviol derivative $10 \mathrm{C}$ on DEN-induced hepatic tumors in the Wistar albino model because the histological structure of liver tumors in this animal closely resembles that of human liver tumors. Induction of hepatocellular carcinomas by DEN in female rats is one of the most frequently used animal models for the investigation of liver carcinogenesis and hepatocellular tumor treatment (71). Liver damage caused by DEN generally reflects instability of liver cell metabolism, which leads to distinctive changes in serum enzyme activities. The biomarkers used in this study provide the measures of carcinogen exposure in rats as an area of high risk for development of hepatocellular carcinoma. Serum AST, ALT, ALP and GGT are sensitive indicators of hepatic injury. Results of this study showed that DEN-treated rats (group II) presented significant increase in serum levels of AST, ALT, ALP, as well as GGT with respect to their control counterparts. The increase in these parameters in rats can be attributed to injury to the structural integrity of the liver and the subsequent leakage of these enzymes into the circulation after cellular damage induced by DEN. In the present investigation, treatment with isosteviol derivative $10 \mathrm{C}$ significantly lowered the activities of these enzymes to near 
normal values suggesting that it may eliminate the hepatotoxic effect of the DEN. Biochemical and histopathological analyses revealed that our Isosteviol derivative $10 \mathrm{C}$ was non-toxic in animals bearing liver cancer. In conclusion, our studies revealed that isosteviol derivative induced its cytotoxic effects through increases cyclin dependent kinase inhibitor 1A (p21) protein levels, CASPASE-3 levels and PARP 1 protein levels which suggest apoptosis pathway. Furthermore, it induces inhibition of angiogenesis through decreased expression of COX2 and VEGF protein levels as a possible pathway of its cytotoxic effect. In addition, it does not induce any apparent toxicity in treated animals and seems to be promising in the management of liver cancer under the present experimental set up.

\section{Acknowledgements}

This work is funded by Science and Technology Development Fund (STDF), project ID 3684, Cairo, Egypt.

\section{References}

1 Thoppil $\mathrm{R}$ and Bishayee A: Terpenoids as potential chemopreventive and therapeutic agents in liver cancer. World $\mathrm{J}$ Hepatol 3(9): 228-249, 2011.

2 Tan X, Xia H, Xu J, and Cao J: Induction of apoptosis in human liver carcinoma HepG2 cell line by 5-allyl-7-gen-difluoromethylenechrysin. World J Gastroenterol 15(18): 2234-2239, 2009.

3 Andreana L, Isgro G, Marelli L, Davies N, Yu D, Navalkissoor $\mathrm{S}$ and Burroughs A: Treatment of hepatocellular carcinoma (HCC) by intra-arterial infusion of radioemitter compounds: trans-arterial radio-embolisation of HCC. Cancer Treat Rev 38(6): 641-649, 2012.

4 Alisi A and Balsano C: Enhancing the efficacy of hepatocellular carcinoma chemotherapeutics with natural anticancer agents Nutr Rev 65(12): 550-553, 2007.

5 Masuzaki R, Yoshida H, Tateishi R, Shiina S and Omata M: Hepatocellular carcinoma in viral hepatitis: improving standard therapy. Best Pract Res Clin Gastroenterol 22(6): 1137-1151, 2008.

6 Shiina S, Tateishi R, Arano T, Uchino K, Enooku K, Nakagawa H, Asaoka Y, Sato T, Masuzaki R, Kondo Y, Goto T, Yoshida H, Omata $\mathrm{M}$ and Koike $\mathrm{K}$ : Radiofrequency ablation for hepatocellular carcinoma: 10-year outcome and prognostic factors. Am J Gastroenterol 107(4): 569-577, 2012.

7 Beppu T, Sugimoto K, Shiraki K, Tameda M, Kusagawa S, Nojiri K, Tanaka J, Yamamoto N, Takei Y, Takaki H, Uraki J, Nakatsuka A, Yamakado K and Takeda K: Clinical significance of tumor markers in detection of recurrent hepatocellular carcinoma after radiofrequency ablation. Int J Mol Med 26(3): 425-433, 2010.

8 Johnson P: Non-surgical treatment of hepatocellular carcinoma. HPB 7(1): 50-55, 2005.

9 Liu B, Wang G, Yang J, Pan X, Yang Z and Zang L: Berberine inhibits human hepatoma cell invasion without cytotoxicity in healthy Hepatocytes. PLoS One 6(6): e21416, 2011.
10 Chung TW, Lee YC and Kim CH: Hepatitis B viral HBx induces matrix metalloproteinase-9 gene expression through activation of ERK and PI-3K/AKT pathways: involvement of invasive potential. FASEB J 18(10): 1123-1125, 2004.

11 Benner S and Hong W: Clinical chemoprevention: developing a cancer prevention strategy. J Nat Cancer Inst 85(18): 1446-1447, 1993.

12 Wong K, Lin J, Liu J, Yang H, Kao P, Chen C, Loh S, Chiu W, Cheng T, Lin J and Hong $\mathrm{H}$ : Antiproliferative effect of isosteviol on angiotensin-II-treated rat aortic smooth muscle cells. Pharmacology 76(4): 163-169, 2006.

13 Mizushina Y, Akihisa T, Ukiya M, Hamasaki Y, MurakamiNakai C, Kuriyama I, Takeuchi T, Sugawara F and Yoshida H: Structural analysis of isosteviol and related compounds as DNA polymerase and DNA topoisomerase inhibitors. Life Sci 77(17): 2127-2140, 2005.

14 Takasaki M, Konoshima T, Kozuka M, Tokuda H, Takayasu J, Nishino H, Miyakoshi M, Mizutani K and Lee K: Cancer preventive agents. Part 8: Chemopreventive effects of stevioside and related compounds. Bioorg Med Chem 17(2): 600-605, 2009.

15 Simstein R, Burow M, Parker A, Weldon C and Beckman B: Apoptosis, Chemoresistance and Breast Cancer: Insights from the MCF-7 Cell Model System. Exp Biol Med 228(9): 995-1003, 2003.

16 Fulda S, Galluzzi L and Kroemer G: Targeting mitochondria for cancer therapy. Nat Rev Drug Discov 9(6): 447-464, 2010.

17 Ashkenazi A and Dixit V: Death receptors signaling and modulation. Science 281(5381): 1305-1308, 1998.

18 O'Connor L, Harris A and Strasser A: CD95 (FAS/APO-1) and p53 signal apoptosis independently in diverse cell types. Cancer Res 60(5): 1217-1220, 2000.

19 Cory S and Adams JM: The Bcl2 family regulators of the cellular life-or-death switch. Nat Rev Cancer 2(9): 647-656, 2002.

20 Kuwana T, Mackey M, Perkins G, Ellisman M, Latterich M, Schneiter R, Green D and Newmeyer D: BID, BAX, and lipids cooperate to form supramolecular openings in the outer mitochondrial membrane. Cell 111(3): 331-342, 2002.

21 Hartwell LH and Kastan M: Cell cycle control and cancer. Science 266(5192): 1821-1828, 1994.

22 Bertoli C, Skotheim J and de Bruin R: Control of cell cycle transcription during $\mathrm{G} 1$ and $\mathrm{S}$ phases. Nat Rev Mol Cell Biol 14(8): 518-528, 2013.

23 Zaldua N, Llavero F, Artaso A, Gálvez P, Lacerda H, Parada L and Zugaza J: Rac1/p21-activated kinase pathway controls retinoblastoma protein phosphorylation and E2F transcription factor activation in B lymphocytes. FEBS J 283(4): 647-661, 2016.

24 Wang Y, Fisher J , Mathew R, Ou L, Otieno S, Sublet J, Xiao L, Chen J, Roussel MF and Kriwacki RW: Intrinsic disorder mediates the diverse regulatory functions of the Cdk inhibitor p21. Nat Chem Biol 7(4): 214-221, 2011.

25 Liu B, Jian Z, Li Q, Li K, Wang Z, Liu L, Tang L, Yi X, Wang $\mathrm{H}, \mathrm{Li} \mathrm{C}$ and Gao T: Baicalein protects human melanocytes from $\mathrm{H}_{2} \mathrm{O}_{2}$-induced apoptosis via inhibiting mitochondria-dependent caspase activation and the p38 MAPK pathway. Free Radic Bio Med 53(2): 183-193, 2012.

26 Danial N: BCL-2 family proteins: critical checkpoints of apoptotic cell death. Clin Cancer Res 13(24): 7254-7263, 2007.

27 Huerta S, Gao X, Dineen S, Kapur P, Saha D and Meyer J: Role of p53, BAX, p21, and DNA-PKcs in radiation sensitivity of HCT-116 cells and xenografts. Surgery 154(2): 143-151, 2013. 
28 Yu S, Andrabi S, Wang H, Kim N, Poirier G, Dawson T and Dawson V: Apoptosis-inducing factor mediates poly (ADPribose) (PAR) polymer-induced cell death. Proc Natl Acad Sci USA 103(48): 18314-18319, 2006.

29 Moubarak R, Yuste V, Artus C, Bouharrour A, Greer P, Menissier-de Murcia J and Susin S: Sequential activation of poly (ADP-ribose) polymerase 1, calpains, and BAX is essential in apoptosis-inducing factor-mediated programmed necrosis. Mol Cell Biol 27(13): 4844-4862, 2007.

30 Doti N, Reuther C, Scognamiglio PL, Dolga AM , Plesnila N, Ruvo $M$ and Culmsee C: Inhibition of the AIF/CypA complex protects against intrinsic death pathways induced by oxidative stress. Cell Death Dis 16(5): e993, 2014.

31 Lui $\mathrm{J}$ and Kong S: Heat shock protein 70 inhibits the nuclear import of apoptosis-inducing factor to avoid DNA fragmentation in TF-1 cells during erythropoiesis. FEBS Lett 581(1): 109-117, 2007.

32 Li C, Zhou Z, Lin R, Zhu D, Sun Y, Tian L, Li L, Gao Y and Wang S: Beta-sitosterol decreases irradiation-induced thymocyte early damage by regulation of the intracellular redox balance and maintenance of mitochondrial membrane stability. J Cell Biochem 102(3): 748-758, 2007.

33 Fang F, Gong P, Zhao H, Bi Y, Zhao G, Gong S and Wang Z: Mitochondrial modulation of apoptosis induced by low-dose radiation in mouse testicular cells. Biomed Environ Sci 26(10): 820-830, 2013.

34 Marnett L: Cyclooxygenase mechanisms. Curr Opin Chem Biol 4(5): 545-552, 2000.

35 Smith W, DeWitt D and Garavito R: Cyclooxygenases: Structural, cellular, and molecular biology. Annu Rev Biochem 69: 145-182, 2000.

36 Wang D and Dubois R: Prostaglandins and cancer. Gut 55(1): 115-122, 2006.

37 Yang Y, Zhu J, Gou H, Cao D, Jiang M and Hou M: Clinical significance of Cox-2, Survivin and Bcl-2 expression in hepatocellular carcinoma (HCC). Med 28(3): 796-803, 2011.

38 Erdem H, Gündogdu C and Sipal S: Correlation of E-cadherin, VEGF, COX-2 expression to prognostic parameters in papillary thyroid carcinoma. Exp Mol Pathol 90(3): 312-317, 2011.

39 Raspollini M, Amunni G, Villanucci A, Boddi V, Baroni G, Taddei A and Taddei G: Expression of inducible nitric oxide synthase and cyclooxygenase- 2 in ovarian cancer: Correlation with clinical outcome. Gynecol Oncol 92(3): 806-812, 2004.

40 Shi $\mathrm{H}, \mathrm{Xu} \mathrm{J}, \mathrm{Hu} \mathrm{N}$ and $\mathrm{Xie} \mathrm{H}$ : Prognostic significance of expression of cyclooxygenase- 2 and vascular endothelial growth factor in human gastric carcinoma. World J Gastroenterol 9(7): 1421-1426, 2003.

41 Karray-Chouayekh S, Trifa F, Khabir A, Boujelbene N, SellamiBoudawara T, Daoud J, Frikha M, Gargouri A and MokdadGargouri R: Methylation status and overexpression of COX-2 in Tunisian patients with ductal invasive breast carcinoma. Tumour Biol 32(3): 461-468, 2011.

42 Lim S, Lee T, Choi C, Ryu S, Min Y and Kim K: Prognostic significance of cyclooxygenase-2 expression and nuclear p53 accumulation in patients with colorectal cancer. J Surg Oncol 97(1): 51-56, 2008.

43 Shamma A, Yamamoto H, Doki Y, Okami J, Kondo M, Fujiwara Y, Yano M, Inoue M, Matsuura N, Shiozaki H and Monden M: Up-regulation of cyclooxygenase-2 in squamous carcinogenesis of the esophagus. Clin Cancer Res 6(4): 1229-1238, 2000.
44 Lazar D, Taban S, Ardeleanu C, Simionescu C, Sporea I, Cornianu $\mathrm{M}$ and Vernic $\mathrm{C}$ : Immunohistochemical expression of the cyclooxygenase- 2 (COX-2) in gastric cancer: The correlations with the tumor angiogenesis and patients' survival. Rom J Morphol Embryol 49(3): 371-379, 2008.

45 Ding S, Li C, Lin S, Han Y, Yang Y, Zhang Y, Li L, Zhou L and Kumar S: Distinct roles of VEGF-A and VEGF-C in tumor metastasis of gastric carcinoma. Oncol Rep 17(2): 369-375, 2007.

46 Nikiteas N, Tzanakis N, Theodoropoulos G, Atsaves V, Christoni Z, Karakitsos P, Lazaris A, Papachristodoulou A, Klonaris C and Gazouli M: Vascular endothelial growth factor and endoglin (CD-105) in gastric cancer. Gastric Cancer 10(1): 12-17, 2007.

47 Vinay K, Fausto N and Abul Abbas: Robbins \& Cotran: Pathologic Basis of Disease. Philadelphia, PA, Saunders Elsevier, 2004.

48 Abeloff M, Armitage J, Niederhuber J, Kastan M and McKenna W: Clinical Oncology. Philadelphia, Pa., Saunders Elsevier, 2008.

49 Wörns $M$ and Galle P: Novel inhibitors in development for hepatocellular carcinoma. Expert Opin investing Drugs 19(5): 615-629, 2010.

50 Korbakis D and Scorilas A: Quantitative expression analysis of the apoptosis-related genes BCL2, BAX and BCL2L12 in gastric adenocarcinoma cells following treatment with the anticancer drugs cisplatin, etoposide and taxol. Tumour Biol 33(3): 865-875, 2012.

51 Nagata $S$ and Golstein P: The Fas death factor. Science 267(5203): 1449-1456, 1995.

52 Niculescu A, Chen X, Smeets M, Hengst L, Prives $C$ and Reed $\mathrm{S}$ : Effects of p21 (Cip1/Waf1) at both the $\mathrm{G}_{1} / \mathrm{S}$ and the $\mathrm{G}_{2} / \mathrm{M}$ cell cycle transitions: $p R b$ is a critical determinant in blocking DNA replication and in preventing endoreduplication. Mol Cell Biol 18(1): 629-643, 1998.

53 Henley S and Dick F: The retinoblastoma family of proteins and their regulatory functions in the mammalian cell division cycle. Cell Division 7(1): 10, 2012.

54 Smith WL and Langenbach R: Why there are two cyclooxygenase isozymes. J Clin Invest 107(12): 1491-1495, 2001.

55 Rahman M, Dhar D, Yamaguchi E, Maruyama S, Sato T, Hayashi H, Ono T, Yamanoi A, Kohno $\mathrm{H}$ and Nagasue $\mathrm{N}$ : Coexpression of inducible nitric oxide synthase and COX-2 in hepatocellular carcinoma and surrounding liver: possible involvement of COX-2 in the angiogenesis of hepatitis $\mathrm{C}$ virus positive cases. Clin Cancer Res 7(5): 1325-1332, 2001.

56 Koga H, Sakisaka S, Ohishi M, Kawaguchi T, Taniguchi E, Sasatomi K, Harada M, Kusaba T, Tanaka M, Kimura R, Nakashima Y, Nakashima O, Kojiro M, Kurohiji T and Sata M: Expression of cyclooxygenase-2 in human hepatocellular carcinoma: relevance to tumor dedifferentiation. Hepatology 29(3): 688-896, 1999.

57 Han C, Michalopoulos G and Wu T: Prostaglandin E2 receptor EP1 transactivates EGFR/MET receptor tyrosine kinases and enhances invasiveness in human hepatocellular carcinoma cells. J Cell Physiol 207(1): 261-270, 2006.

58 Gallo O, Franchi A, Magnelli L, Sardi I, Vannacci A, Boddi V, Chiarugi V and Masini E: Cyclooxygenase-2 pathway correlates with VEGF expression in head and neck cancer: Implications for tumor angiogenesis and metastasis. Neoplasia 3(1): 53-61, 2001.

59 Amano H, Haysahi I, Yoshida S, Yoshimura H and Majima M: Cyclooxygenase- 2 and adenylate cyclase/protein kinase A signaling pathway enhances angiogenesis through induction of vascular endothelial growth factor in rat sponge implants. Hum Cell 15(1): 13-24, 2002. 
60 Cheng A, Chan H, To K, Leung W, Chan K, Liew C and Sung $\mathrm{J}$ : Cyclooxygenase-2 pathway correlates with vascular endothelial growth factor expression and tumor angiogenesis in hepatitis B virus-associated hepatocellular carcinoma. Int J Oncol 24(4): 853-860, 2004.

61 Tang T, Poon R, Lau C, Xie D and Fan ST: Tumor cyclooxygenase-2 levels correlate with tumor invasiveness in human hepatocellular carcinoma. World J Gastroenterol 11(13): 1896-1902, 2005.

62 Salvesen $\mathrm{G}$ and Dixit V: Caspases: intracellular signaling by proteolysis. Cell 91(4): 443-446, 1997.

63 Tewari M, Quan L, O'Rourke K, Desnoyers S, Zeng Z, Beidler D, Poirier G, Salvesen G and Dixit V: Yama/CPP32 beta, a mammalian homolog of CED-3, is a CrmA-inhibitable protease that cleaves the death substrate poly (ADP-ribose) polymerase. Cell 81(5): 801-809, 1995

64 Germain M, Affar E, D'Amours D, Dixit V, Salvesen G and Poirier G: Cleavage of auto modified poly (ADP-ribose) polymerase during apoptosis. Evidence for involvement of caspase-7. J Biol Chem 274(40): 28379-28384, 1999.

65 Wei Y, Van Nhieu J, Prigent S, Srivatanakul P, Tiollais P and Buendia M: Altered expression of E-cadherin in hepatocellular carcinoma: correlations with genetic alterations, beta-catenin expression, and clinical features. Hepatology 36(3): 692-701, 2002.

66 Cui J, Zhou X, Liu Y, Tang Z and Romeih M: Wnt signaling in hepatocellular carcinoma: analysis of mutation and expression of beta-catenin, T-cell factor-4 and glycogen synthase kinase 3beta genes. J Gastroenterol Hepatol 18(3): 280-287, 2003.
67 Harada N, Oshima H, Katoh M, Tamai Y, Oshima M and Taketo M: Hepatocarcinogenesis in mice with beta-catenin and Ha-ras gene mutations. Cancer Res 64(1): 48-54, 2004.

68 Inagawa S, Itabashi M, Adachi S, Kawamoto T, Hori M, Shimazaki J, Yoshimi F and Fukao K: Expression and prognostic roles of beta-catenin in hepatocellular carcinoma: correlation with tumor progression and postoperative survival. Clin Cancer Res 8(2): 450-456, 2002.

69 Hsu H, Jeng Y, Mao T, Chu J, Lai P and Peng S: Beta-catenin mutations are associated with a subset of low-stage hepatocellular carcinoma negative for hepatitis B virus and with favorable prognosis. Am J Pathol 157(3): 763-770, 2000.

70 Buendia M: Genetics of hepatocellular carcinoma. Semin Cancer Biol 10(3): 185-200, 2000.

71 Park D, Shin J, Park S, Seo J, Li L, Jang J and Lee M: Diethylnitrosamine (DEN) induces irreversible hepatocellular carcinogenesis through overexpression of $\mathrm{G}_{1} / \mathrm{S}$-phase regulatory proteins in rat. Toxicol Lett 191(2-3): 321-326, 2009.

Received January 14, 2017

Revised February 26, 2017

Accepted March 3, 2017 